\title{
Comparative Study Between Bupivacaine Infiltration in Inguinal Hernia and Intravenous Narcotic Analgesia A Multicenteric Study
}

\author{
MZ WAHLA AU HAQ F MUMTAZ \\ Department of Surgery: King Edward Medical University/Mayo Hospital, Lahore. \\ ('orrespondence to Dr.Muhammad Zakria Wahla. Senior Registrar.
}

\begin{abstract}
The object of the study was to assess the pain relief after Bupivacaine infiltration in the wound in the patients following hernioraphy and to compare it with patients who received narcotic analgesia. 400 patients were selected, 200 being allocated to each group. Pain was compared according to pain scale and mobility of the patients post operatively. After the first 6 hours patients who received Bupivacaine were mobilized earlier as compared to $2^{\text {nd }}$ group. This shows that long acting local anesthesia can be used in a day care surgery.
\end{abstract}

Key words: Bupivacine, hernia.

Pain has been defined as ' an unpleasant sensory and emotional experience associated with actual or potential tissue damage'. Pain in inguinal hernia wound immediately after operation till next few days is quite common which is due to inadvertent damage to the cutaneous supply of skin and parietal peritoneum.

Apart from the humanitarian aspect, there are several physiological reasons for treating postoperative pain. Functional residual capacity and ability to cough and deep breath is decreased postoperatively. This in turn can lead to retention of secretions, atelectasis and pneumonia. Mobilization of patient may be delayed post operatively if patient is experiencing pain. This may in turn increase their risk of developing deep vein thrombosis and also prolong the hospital stay. Postoperative wound pain is relieved by two ways; one is by parenteral analgesia and other by local analgesia. Parenteral analgesia is either in the form of non-steroidal anti-inflammatory drugs or narcotic analgesia. The non-steroidal anti-inflammatory drugs are very useful for managing mild to moderate pain. But they can cause gastric ulceration and fluid retention by kidneys. Narcotic analgesia is very useful in controlling moderate to severe pain and is usually administered through intravenous as well as intra-muscular route. But unfortunately there are several adverse effects. These agents cause respiratory center depression and hence it leads to retention of alveolar secretions, atelectasis and pneumonia.

Long acting local anesthesia like injection Bupivacaine infiltration in the wound helps in relieving the pain by blocking the neuronal conduction ${ }^{2}$. The use of local anesthetics significantly decreases patient's duration of stay in the hospital postoperatively.

Postoperative pain in the inguinal hernia is very troublesome for the patient and it should be managed immediately without causing any side effects of the analgesia. Patient should be mobilized as soon as possible $e^{3,4}$. This is the basis of day case surgery of inguinal hernia in the modern world $5.6,7$.
Material and methods:

It was an experimental study with the patients randomly allocated to either of the treatments using simple random sampling. All the patients were admitted through the emergency and the OPD of the South Surgical Ward Mayo Hospital and Services Hospital Lahore from 4-10-2001 to 4-10-2002. Out of all the inguinal hernias patients 400 patients were selected, 92 admitted through emergency and 308 from outdoor. According to inclusion criteria, all patients were above 12 years of age while those patients sensitive to Bupivacaine or severe cardiac problems were excluded from the study. All patients fulfilling the criteria of selection were randomly allocated to either of the treatment using simple random sampling. 200 patients were allocated to each group. The first group received Injection Bupivacaine infiltration in the wound; Pain was compared according to pain scale and mobility of patients 6 hourly for 24 hours post operatively with second group who received narcotic analgesia intravenously. So post operative pain relief and mobility of patients were two variables.

Dose of injection Bupivacaine was $3 \mathrm{mg} / \mathrm{kg}$ body weight, which was administered by doctor at the wound site postoperatively every 6 hourly.

Dose of narcotic analgesia was 10mg 8 hourly Intravenously. The pain relief or effects of the local anesthesia were monitored at Verbal Rating Score (VRS) being 1) No Pain 2) Mild Pain 3) Moderate Pain 4) Severe Pain

Time of mobilization of patient was noted post operatively after every six hours

Data analysis is recorded in table having following parameters

1. Symptoms control (pain relief) according to pain score (VRS)

2. Time of mobilization of patient post operatively

Results:

Most of the patients developing the disease were more than 30 years of age and all were male patients. $268(67 \%)$ patients had right inguinal hernia and $132(33 \%)$ had left 
sided inguinal hernia. Both types of hernias were evenly distributed in two groups. $308(77 \%)$ patients were admitted through outdoor and 92(23\%) patients were admitted through emergency with obstructed inguinal hernia. Later on the hernias were reduced on conservative management and then these patients were operated on elective list. 32(8\%) patients had chronic liver disease. $48(12 \%)$ patients had chronic obstructive airway disease. $20(5 \%)$ patients had history of constipation and $28(7 \%)$ patients had history of bladder outflow obstruction. $272(68 \%)$ patients did not have any associated disease. In both groups, there was no difference in mobilization of patient postoperatively in first 6 hours but in subsequent hours those patients who received injection Bupivacaine were mobilized earlier then those who received Nalbuphine. (28\% versus $10 \%$ in second 6 hours).

Postoperative pain with Bupivacaine was controlled very well and it was equally effective as Nalbuphine in controlling pain. With the use of injection Bupivacaine only $4 \%$ patients had severe pain and $48 \%$ patients had mild pain against $2 \%$ and $42 \%$ patients who used injection Nalbuphine respectively.

\section{Discussion:}

From the results of the study we have seen that mild to moderate postoperative pain is significantly reduced with bupivacain. Fischer $\mathrm{S} \mathrm{et}^{8}$ al in his study concluded that Bupivacaine infiltration is an effective and safe method of reducing postoperative pain and analgesic consumption after the inguinal hernia repair. Abad-Torrent $\mathrm{A}$ et al ${ }^{(9)}$ has also supported this study. Victory RA et $\mathrm{al}^{10}$ explained effect of infiltration of Bupivacaine on postoperative pain and concluded that it had clinically significant effect on reducing pain scores and analgesic requirement following abdominal hysterectomy.

Callesen $\mathrm{T}^{11}$ et al in his study on influence of surgical technique on pain after primary inguinal hernioraphy has concluded that choice of surgical technique for open repair of a primary indirect inguinal hernia has no influence on postoperative pain. Aasbo $\mathrm{V}$ et $\mathrm{al}^{12}$ in his study on Improved long lasting postoperative analgesia, recovery function and patient satisfaction after inguinal hernia repair with inguinal field block compared with general anesthesia, concluded that preoperative inguinal field block for hernia repair provided benefits for patients in terms of faster recovery, less pain, better mobilization and higher satisfaction throughout the whole first postoperative week. From the results it is also clear that Bupivacaine is as effective in controlling pain as narcotic analgesia. Cheong WK et $\mathrm{al}^{13}$ conducted a study on randomized clinical trial of local Bupivacaine perfusion versus parenteral morphine infusion for pain relief after laparotomy, proved that direct continuous local wound perfusion of Bupivacaine is as effective as narcotic analgesia for postoperative pain relief after laparotomy. It is a safe and feasible alternative to parenteral opioids.
Waechter $\mathrm{FL}$ et $\mathrm{al}^{14}$ in a study on comparison between topical and infiltrative Bupivacaine and intravenous meperidine for postoperative analgesia after inguinal herniorrhaphy proved that the simple instillation of local anesthetic allows better analgesic evolution of the surgical wound after the first 24 hours considering the lower rate of resulting complications and this is the basis of day case surgery. Ozgun Het $\mathrm{al}^{6}$ also supported this study and explains that there are less postoperative complications with Bupivacaine than narcotic analgesia. An understanding of the pharmacokinetic properties, as well as issues related to opioids rotation, tolerance, dependence, and addiction are essential aspects of the clinical pharmacology of opioids for pain. Inturrisi CE et al ${ }^{(15)}$ in his study fully explained these aspects of narcotic analgesia and it is because of these complications with narcotic analgesia that duration of patient's stay in the hospital is increased.

\section{Conclusion:}

This study shows that Injection Bupivacaine infiltration is equally effective in controlling pain as narcotic analgesia but those patients who had received Bupivacaine in the wound were mobilized earlier then those who received narcotic analgesia. This shows that long acting local anesthesia can be used in a day case surgery. There is need to explore new yet economical modalities of treating postoperative pain. Use of local anesthesia can play a very important role in treating pain.

\section{References:}

1. Kirk R M. The Management of Postoperative Pain: Clinical Surgery In General. $3^{\text {rd }}$ ed. Churchill Livingstone. 1999; 326-328

2. Guyton AC, Hall JE.Somatic sensations: Textbook of medical physiology. $10^{\text {th }}$ ed. WB Saunders. 2000; 540563.

3. Ding $Y$, White PF. Post-herniorrhaphy pain in outpatients after pre-incision ilioinguinal-hypogastric nerve block during monitored anesthesia care. Can J Anaesth $1995 ; 42: 12-5$

4. Langer JC, Shandling B, Rosenberg M. Intraoperative Bupivacaine during outpatient hernia repair in children: a randomized double blind trial. J Pediatr Surg. $1987 ; 22: 267-70$

5. Wheatley SA, Millar JM, Jadad AR. Reduction of pain after laparoscopic sterilization with local Bupivacaine: a randomized, parallel, double-blind trial. Br J Obstet Gynaecol 1994 ;101:443-6

6. Ozgun H, Kurt MN, Kurt I, Cevikel MH. Comparison of local, spinal, and general anesthesia for inguinal herniorrhaphy. Eur J Surg. 2002;168:455-9

7. Spittal MJ, Hunter SJ. A comparison of Bupivacaine instillation and inguinal field block for control of pain after herniorrhaphy. Ann R Coll Surg. Engl 1992 ;74:85-8 
8. Fischer S, Troidl H, Maclean AA, Koehler L, Paul A. Prospective double-blind randomized study of a new regimen of pre-emptive analgesia for inguinal hernia repair: evaluation of prospective pain course. Eur J Surg.2000:166:545-51

9. Abad-Torrent A, Calabuig R, Sueiras A, Casasin T, Ramon C, Pelegri D, Izquierdo E, Faura A, Linares MJ. [Efficacy of the ilioinguinal and iliohypogastric block in the treatment of the postoperative pain of inguinal herniorrhaphy] Rev Esp Anestesiol Reanim $1996 ; 43: 318-20$

10. Victory RA, Gajraj NM, Van Elstraete A, Pace NA, Johnson ER, White PF. Effect of preincision versus postincision infiltration with Bupivacaine on postoperative pain. J Clin Anesth. 1995 ; 7:192-6

11. Callesen T, Bech K, Andersen J, Nielsen R, Roikjaer $\mathrm{O}$, Kehlet $\mathrm{H}$. Pain after primary inguinal herniorihaphy: influence of surgical technique I Am Coll Surg. $1999 ; 188: 355-9$

12. Aasbo V, Thuen A, Raeder J. Improved long-lasting postoperative analgesia, recovery function and patient satisfaction after inguinal hernia repair with inguinal field block compared with general anesthesia. Acta Anaesthesiol Scand $2002 ; 46: 674-8$

13. Cheong WK, Seow-Choen F, Eu KW, Tang CL, Heah SM. Randomized clinical trial of local Bupivacaine perfusion versus parenteral morphine infusion for pain relief after laparotomy. Br J Surg $2001 ; 88(3): 357-9$

14. Waechter FL, Sampaio JA, Pinto RD, Alvares-DaSilva MR, Pereira-Lima L. A comparison between topical and infiltrative Bupivacaine and intravenous meperidine for postoperative analgesia after inguinal herniorrhaphy. Am Surg. 2001; 67:447-50.

15. Inturrisi CE. Clinical pharmacology of opioids for pain. Clin J Pain 2002;18:S3-13 